REVISTA ANDALUZA DE ANTROPOLOGÍA.

NÚMERO 2: PATRIMONIO CULTURAL Y DERECHOS COLECTIVOS.

MARZO DE 2012

ISSN 2174-6796

[pp. 48-67]

http://dx.doi.org/10.12795/RAA.2012.i02.03

Fecha de recepción: 16/11/2011

Fecha de aceptación: 18/01/2012

\title{
DERECHOS HUMANOS, DERECHO A LA CULTURA Y PUEBLOS INDÍGENAS.
}

\section{JUAN ANTONIO SENENT DE FRUTOS}

Universidad de Sevilla

\section{Resumen.}

Tratamos aquí el problema de la relación entre pueblos indígenas y los derechos humanos enfocando esta relación desde el derecho a la cultura y tratando de aportar un planteamiento radical del problema de base. Las cuestiones derivadas del derecho al patrimonio cultural hay que situarlas en el contexto mayor del derecho a la cultura o al proceso de autodeterminación cultural. El problema radical que hay que identificar para poder hacer un tratamiento postcolonial del problema es la negación de la capacidad para producir cultura y, con ello, para autodeterminarse culturalmente en las relaciones jurídicas, políticas. Para ello, primero trazamos una genealogía histórico-cultural del proceso de conquista del mundo a partir de la modernidad liberal, tomando como referencia de construcción de narrativa excluyente la obra de John Locke. Y segundo, situamos el problema normativo actual en relación a la cultura desde la lucha que se da entre los diferentes actores y marcos socio-jurídicos actuales.

Palabras claves: Derechos humanos, derecho a la cultura, pueblos indígenas, modernidad 
liberal, John Locke, autodeterminación cultural.

\begin{abstract}
.
Try here the problem of the relationship between indigenous peoples and human rights focusing this relationship from the right to culture and trying to bring a radical approach to the basic problem. Issues arising from the right to cultural heritage must be placed in the context of the right to culture or cultural self-determination process. The radical problem which should be identified in order to make a post-colonial treatment of the problem is its ability to produce culture, and thus denial to self-determine culturally in legal, political relations. To do this, we first draw a cultural-historical genealogy of the process of conquest of the world from the liberal modernity, by construction of exclusive narrative reference to the work of John Locke. And second, put the current regulatory problem in relation to culture from the fight that occurs between the different actors and current socio-legal frameworks.
\end{abstract}

Keywords: Human rights, right to culture, indigenous peoples, John Locke, liberal modernity, cultural self-determination

\title{
1. PLANTEAMIENTO Y CONTEXTUALIZACIÓN
}

En este artículo nos situamos en la línea de la crítica que tanto en filosofía, teología como en ciencias sociales se viene desarrollando en y desde los contextos socioculturales subalternos en las últimas décadas del siglo XX frente al paradigma de racionalidad moderno que pretende erigirse en única fuente legítima de normatividad y de producción del mundo humano. Se trata de una perspectiva que pretende descubrir y desenmascarar las funciones ideológicas de un saber y de una racionalidad particular que se erige dogmáticamente en expresión natural, universal y ahistórica de lo humano, para con ello, ayudar a descolonizar los sistemas sociales y culturales dominados, que son autores negados o minorizados de su propio proceso de reproducción y recreación de su vida social ${ }^{1}$.

En este contexto crítico, vamos a plantear el problema de la relación entre pueblos indígenas y los derechos humanos; enfocando esta relación desde el derecho a la cultura de una forma sumaria, pues son muchos los ejercicios críticos que se han hecho, pero tratando de aportar un planteamiento radical del problema de base. Los "derechos humanos" no se entienden aquí sólo ni primariamente como referencias normativas ilustradas, sino como proceso social de lucha y afirmación por la vida en sus diversas

1. Como contexto crítico más inmediato utilizo el planteamiento metodológico de Ellacuría (19301989), quien emplea y fundamenta una metodología que permite descolonizar el planteamiento moderno del problema de los derechos humanos. Puede consultarse en Senent (1998) y para un conocimiento de los trabajos de Ellacuría puede consultarse La lucha por la justicia (2012), ed. de J. A. Senent. 
manifestaciones y dimensiones. Las cuestiones derivadas del derecho al patrimonio cultural hay que situarlas en el contexto mayor del derecho a la cultura o al proceso de autodeterminación cultural. A nuestro juicio, el problema de base y radical que hay que identificar para poder hacer un tratamiento postcolonial del problema es la negación de la capacidad para producir cultura y, con ello, para autodeterminarse culturalmente en las relaciones jurídicas, políticas, económicas, ecológicas o espirituales de los pueblos no originariamente occidentales. A partir de ahí, puesto que son actores marginados o tutelados, sin capacidad para regular y definir su mundo, se les impone un marco normativo ( heterocultural) desde el que supuestamente deben autodefinirse y articular su existencia social como si ese marco normativo no fuera fruto de unas opciones culturales determinadas y portadoras de un proyecto civilizatorio global que está al servicio de grupos sociales que se benefician de la negación y exclusión de los otros para favorecer sus propias estrategias de acumulación de bienes o de conquista del mundo conocido.

Desde aquí abordaré este artículo en dos partes. Una primera, donde trazaré una genealogía histórico-cultural del proceso de conquista cultural a partir de la modernidad liberal (que continúa vigente como proyecto hegemónico en el proceso de globalización de las relaciones humanas), tomando como construcción de narrativa excluyente y modelo normativo inspirador la obra de John Locke (1632-1704). Y una segunda, donde situaré el problema normativo actual en relación a la cultura desde la lucha que se da entre los diferentes actores y marcos socio-jurídicos actuales.

\section{FUNDAMENTOS IDEOLÓGICOS DE LA COLONIZACIÓN MODERNA DEL PROCESO DE AUTODETERMINACIÓN CULTURAL}

La obra de John Locke nos permite visualizar de forma rápida y panorámica la constitución normativa de la sociedad moderna y con ella el proceso de colonización del mundo que se despliegan desde las potencias occidentales a partir del Renacimiento, en el inicio del actual proceso de globalización cultural del mundo. El proceso sigue, como sabemos, y los conflictos generados continúan ${ }^{2}$ en el proceso histórico de hacer del mundo conocido un mundo cada vez más global, manejable y al servicio de las élites de la globalización que sacan ventaja del proceso. Esto conlleva un choque inevitable con las otras sociedades no europeas, que se situaban (y tratan todavía de situarse) en otros marcos culturales. Éstas, por tanto, tendrán que ser colonizadas en aras de las exigencias de la nueva civilización moderna. En este sentido, este autor nos permite visualizar los

2. Abordé esta cuestión en Senent (2004: 115-144), y también sobre esa problemática puede verse Sánchez Rubio y Solórzano Alfaro (2004). 
fundamentos de las diversas fases del capitalismo señaladas por K. Polanyi (1997)³. Así justificó tanto el cambio de propiedad de la tierra en Europa, y, con ello, la mutación de su sentido social, como también la colonización de las tierras de los llamados "pueblos salvajes" por la civilización de los pueblos europeos. Pero a su vez, apoya la contracción etnocéntrica de la idea de género humano a los "pueblos civilizados", la negación de los productos culturales de otros pueblos y con ello su irrelevancia normativa, y la pérdida de interdependencia entre los seres humanos y la naturaleza. Veamos, pues, las líneas principales de este proceso por medio de algunos de sus supuestos básicos que los podemos definir como "reducciones" con respecto al horizonte cultural anterior de carácter tradicional.

\subsection{Primera reducción: De la tierra como propiedad común del género humano a su apropiación privativa}

Locke desarrolla esta cuestión fundamentalmente en el capítulo 5 ("De la propiedad") de su obra Segundo Tratado sobre el Gobierno Civil (1690). El punto de partida formal es el derecho de propiedad como derecho natural que determinará el modo de relación del ser humano con “la tierra y todas sus criaturas” (cf. \$27). Así, la tierra, sus criaturas o sus productos pasan a ser meros objetos del derecho de los hombres. Se da un proceso de externalización o desvinculación entre el titular del derecho, el género humano y la naturaleza, lo que permite que sea tratada como cosa de la que apropiarse en beneficio propio. Se pasa de la pertenencia a una tierra a la posesión o propiedad sobre cualquier tierra o criatura ${ }^{4}$.

Locke, situándose supuestamente en la misma cosmovisión cristiana de la tradición anterior (cf. \$25), plantea, en cambio, este derecho natural de modo que le permita desentenderse de cualquier dependencia respecto al bien común o de cualquier "hipoteca social" del derecho de propiedad individual, o de la responsabilidad por el cuidado de la naturaleza.

Inicialmente él mismo nos presenta su objetivo: "mostraré cómo los hombres pueden

3. Pero incluso Locke permite justificar las bases del neocolonialismo actual que el capitalismo de la era de la información proyecta sobre los territorios y la biodiversidad que albergan los llamados pueblos "en vías de desarrollo", es decir, pueblos indígenas y sociedades tradicionales. En esta nueva fase de reordenación de las fuerzas productivas, ese conocimiento sobre la biodiversidad que era patrimonio de esos pueblos es un nuevo objeto de interés y de acción depredadora so capa de servicio a la humanidad. Así por ejemplo, la llamada "biopiratería" no se sustenta sobre el expolio y acumulación de los bienes de otros, sino en la apropiación del conocimiento tradicional sobre diversas formas de materia viva identificadas o producidas por los "pueblos atrasados", para su reproducción y explotación en el llamado libre mercado al que sólo tendrán acceso los que tengan capacidad de pago (demanda solvente), y por ello, aun siendo "formalmente" todos iguales, no todos podrán operar en el mercado. Cf. En esta línea Sánchez Rubio y Solórzano Alfaro (2004).

4. Este proceso de transformación cultural en sucesivos pasos y etapas en la era moderna en relación con lo natural lo he analizado en Senent (2010). 
llegar a tener en propiedad varias parcelas de lo que Dios entregó en común al género humano; y ello, sin necesidad de que haya un acuerdo expreso entre los miembros de la comunidad” (\$25). En su planteamiento arranca de un “estado natural” que está más allá de cualquier acuerdo y de cualquier sociedad o individuo. Sobre una hipotética situación originaria Locke comienza su argumentación: "Dios, que ha dado en común el mundo a los hombres, les ha dado también la razón, a fin de que hagan uso de ella para conseguir mayor beneficio de la vida, y mayores ventajas. La tierra y todo lo que hay en ella le fue dada al hombre para soporte y comodidad de su existencia. Y aunque todos los frutos que la tierra produce naturalmente, así como las bestias que de ellos se alimentan, pertenecen a la humanidad comunitariamente, al ser productos espontáneos de la naturaleza; y aunque nadie tiene originalmente un exclusivo dominio privado sobre ninguna de estas cosas tal y como son dadas en el estado natural, ocurre, sin embargo, que como dichos bienes están ahí para uso de los hombres, tiene que haber necesariamente algún medio de apropiárselos antes de que puedan ser utilizados de algún modo o resulten beneficiosos para algún hombre en particular"(\$26).

Dado que hay una disposición en favor del género humano de los bienes naturales, es necesario que esos bienes rindan, y para ello deben ser apropiados individualmente: "Aunque la tierra y todas sus criaturas inferiores pertenecen en común a todos los hombres, cada hombre tiene, sin embargo, una propiedad que pertenece a su propia persona; y a esa propiedad nadie tiene derecho excepto él mismo. El trabajo de su cuerpo y la labor producida por sus manos, podemos decir que son suyos. Cualquier cosa que él saca del estado en que la naturaleza la produjo y la dejó, y la modifica con su labor y añade algo que es de sí mismo, es por consiguiente, propiedad suya (...) y ello hace que no tengan ya derecho a ella los demás hombres" (\$27). Y como señala más adelante, ese ejercicio de apropiación, de practicar el derecho de propiedad individual, se extiende no sólo a las criaturas o a los productos de la tierra, sino que, nos dice Locke, “(...) la cuestión principal acerca de la propiedad de la tierra no se refiere hoy día a los frutos de la tierra ni a las bestias que en ella habitan, sino a la tierra misma al ser ésta la que contiene y lleva consigo todo lo demás, diré que la propiedad de la tierra se adquiere también, como es obvio, del mismo modo que en el caso anterior. Toda porción de tierra que un hombre labre, plante, mejore, cultive y haga que produzca frutos para su uso, será propiedad suya. Es como si, como resultado de su trabajo, este hombre pusiera cercas a esa tierra, apartándola de los terrenos comunales" (\$32).

La tierra, hasta entonces comunal, soporte de la vida común de cada pueblo, y por tanto algo que pertenece a los comuneros, y de la que estos no pueden disponer o enajenar, ni tampoco pueden enajenarse de ella en tanto que también pertenecen a la tierra, es decir, se trataba de una mutua posesión, de una posesión en reciprocidad. Pasa a ser considerada, no ya como terra mater, lugar de nutrición y de identidad como en las 
sociedades tradicionales también europeas, sino como terra nullius, tierra de nadie. El sujeto deja ser parte la tierra, y de una tierra en particular. Como ya no hay vínculos orgánicos, ni sociales ni jurídicos con la tierra, disueltos los vínculos, la tierra se presenta como tierra de nadie, y por tanto apropiable "por cualquiera"5.

Se puede decir que cualquier sujeto humano podría apropiarse privativamente de esos bienes, de quienes en principio se predica una igualdad formal ${ }^{6}$. Cualquiera podría extraer los "productos espontáneos" de la naturaleza. Por tanto, de la propiedad común de la humanidad ("se ha dado en común a toda la humanidad para que esta participe en común de ella” \$25). Algo “común” significará en la situación originaria para Locke "apropiable por cualquiera".

¿Cuál es el ámbito de este "patrimonio común de la humanidad"? Aquel donde la huella de la propiedad privada individual y del sistema legal no haya sacado a la res communis de su estado natural, y por tanto donde todo continúa en estado comunal originario. Este derecho natural previo y fundante de los sistemas de derecho positivo explica para nuestro autor el tránsito del estado natural a la sociedad constituida ${ }^{7}$, pero siempre subsiste en los ámbitos que exceden a la regulación de los sistemas legales: "entre aquellos que se cuentan entre la parte civilizada de la humanidad y que han hecho y multiplicado una serie de leyes positivas para determinar la propiedad, esta ley originaria de la naturaleza que se aplicaba antes a los bienes comunes para establecer los orígenes de la apropiación, sigue siendo vigente” $(\$ 30)^{8}$. Por tanto, al interior de la parte civilizada de la humanidad, apenas quedarían bienes en condición comunal originaria que puedan ser objetos de acción predatoria por cualquiera ${ }^{9}$, pero hacia fuera de los límites geográficos de las mismas, el resto de la tierra ${ }^{10}$ se presenta como un gran bien comunal sobre el que desplegar su acción: "Todavía se encuentran hoy grandes porciones de tierra que,

5. Que es lo que justificará también la colonización de las tierras de los otros pueblos, como veremos (Shiva, 2003).

6. Para explicitar esta igualdad formal, aunque como después veremos no haya una igualdad en la racionalidad, señala: "El fruto o la carne del venado que alimentan al indio salvaje, el cual no ha oído hablar de cotos de caza y es todavía un usuario de la tierra en común con los demás, tienen que ser suyos; y tan suyos, es decir, tan parte de sí mismo, que ningún otro tendrá derecho a ellos antes que su propietario haya derivado algún beneficio que dé sustento a su vida" ( $\$ 26)$.

7. La cual surge, como no deja de recalcar a lo largo de su Segundo Tratado, para preservar la propiedad individual como derecho natural central.

8 . Esto también se proyecta frente a los recursos biológicos de los mares, dado que este espacio constituye "un gran bien comunal" (cf. \$30). Sobre las leyes consuetudinarias y los orígenes de la apropiabilidad, puede verse de Pureza (2002: 169 y ss).

9. Sólo queda algún reducto ya meramente anecdótico: "entre nosotros, la liebre que alguien está cazando, se considera propiedad de aquél que la persigue durante la caza” (\$30).

10. Como destaca Shiva (2003), para este proyecto colonizador europeo la tierra se presentaba como terra nullius, a pesar de que estuviera habitada por otros pueblos. 
al no haberse unido sus habitantes con el resto de la humanidad en el acuerdo de utilizar dinero común, permanecen sin cultivar; y como estas tierras proporcionalmente son mucho mayores que el número de personas que viven en ellas, continúan en estado comunal. Mas esto difícilmente podría darse entre esa parte de la humanidad que ha consentido en la utilización del dinero" (\$45).

Si no se ha adoptado el sistema de relaciones mercantiles propio de las sociedades capitalistas no hay ninguna acción económica ni ninguna acción social y culturalmente integrada; por ello, los individuos "aislados" solo toman los frutos espontáneos, de ahí que no constituya ningún robo a la parte civilizada de la humanidad, ni a los otros habitantes de esas tierras. Esos habitantes son los “indios salvajes" (\$26), que como va ejemplificando a lo largo de sus obras, vienen a corresponder a los otros pueblos que no sean los europeos (vid. infra) y por tanto los territorios objeto de expansión colonial en la era moderna.

Donde no haya por tanto un sistema de leyes positivas o de pactos ${ }^{11}$ al modo europeo, cualquiera se puede apropiar de todo cuanto sea para su utilidad, y ello sin depender del consentimiento de nadie. La acción de sustracción de algo de su condición comunal frente al resto del mundo no lo considera ningún robo, ni depende del consentimiento de quienes habiten las tierras, ni estos poseen ninguna forma de propiedad común sobre los bienes naturales, ni tienen ningún pacto explícito o implícito sobre la forma de aprovechamiento de los recursos naturales que emplean para el sustento de sus vidas. Si Locke reconociera alguna institucionalización social o jurídica sobre el uso de estos bienes por parte de esos habitantes toda su justificación de la acción colonial en la era moderna sobre los recursos de otros pueblos perdería su justificación, y tendría que reconocer su ilicitud: "Ciertamente, quien se ha alimentado (...) de las manzanas que ha cosechado de los árboles del bosque, puede decirse que se ha apropiado de ellas. Nadie podrá negar que ese alimento es suyo (...) ¿Podrá decir alguno que este hombre no tenía derecho a las manzanas que él se apropió de este modo, alegando que no tenía consentimiento de todo el género humano para tomarlas en pertenencia? ¿Fue un robo el apropiarse de lo que pertenecía comunitariamente a todos? Si el consentimiento de todo el género humano hubiera sido necesario, este hombre se habría muerto de hambre” (\$28).

Con una razón humanitaria se desentiende a partir de ahí de cualquier exigencia en favor del bien común de la humanidad, y por supuesto de cualquier respeto a los territorios de los pueblos en los que se despliega su acción. En Inglaterra, el régimen de los comuneros

11. "Es cierto que en las tierras comunales de Inglaterra o de cualquier otro país en el que mucha gente con dinero y con comercio vive bajo un gobierno, nadie puede cercar o apropiarse parcela alguna sin el consentimiento de todos los copropietarios. Pues esas tierras llegaron a ser comunales mediante pacto, es decir, por la ley de la tierra, la cual no debe ser violada. Y aunque estos terrenos sean comunales con respecto a algunos hombres, no lo son respecto de la humanidad; sólo son propiedad común dentro de un país determinado, o de una parroquia” (\$35). 
debe ser respetado (cf. \$35), de ninguna manera en otros pueblos no civilizados, pues si en el primer caso hay una costumbre jurídica no así en el segundo caso ya que sobre estas posesiones comunales únicamente rige la ley natural ${ }^{12}$, y por tanto está liberado del consentimiento de los comuneros, encontrándose ante una res nullius y no ante bienes protegidos por ningún sistema de derecho positivo. Lo que en Inglaterra es robo (y en las otras sociedades civilizadas), no lo es fuera de sus fronteras legales porque no hay restricciones más allá del régimen de derecho natural. Los bienes que emplean para su sustento otros pueblos sí están sometidos a un régimen abierto de apropiación para "toda la humanidad", no así los bienes de los primeros, ni siquiera los que aún permanecen en condición comunal.

\subsection{Segunda reducción: De la universalidad de la racionalidad "género humano" a la racionalidad de los "pueblos civilizados"}

La obra de Locke nos muestra cómo en la tradición liberal, en la que él se sitúa y en buena medida ayuda a fundamentar, tras el discurso universalista y abstracto (que arranca formalmente de un punto de partida general, basándose en referencias tales como humanidad, género humano, naturaleza humana, o racionalidad humana, y por tanto compartible por cualquiera); sin embargo, desde ahí consigue derivar y llegar a lo que críticamente podríamos denominar como una reducción social y cultural de lo humano. Con esta reducción o asimilación de un único patrón cultural como exponente de la auténtica racionalidad humana consigue desentenderse de buena parte de la humanidad, y, por ello, la eventual explotación de los recursos naturales o culturales de los que no practiquen su lógica cultural de utilización de estos recursos no será imposición ni exclusión de parte de la humanidad, sino servicio a la verdadera humanidad.

Dice Locke: "Dios ha dado a los hombres el mundo en común; pero como se lo dio para su beneficio y para que sacaran de él lo que más les conviniera para su vida, no podemos suponer que fuese intención de Dios dejar que el mundo permaneciese en terreno comunal $y$ sin cultivar. Ha dado el mundo para que el hombre trabajador y racional lo use; $y$ es el trabajo lo que da derecho a la propiedad, y no los delirios y la avaricia de los revoltosos y los pendencieros" (\$34).

¿Quién es el hombre trabajador y racional y quiénes son esos individuos avariciosos y pendencieros? Los primeros, los pertenecientes a las sociedades burguesas (cf. \$35) o la "parte civilizada de la humanidad" (\$30); y por la otra parte, está hablando de los

12. Por tanto se realiza una reducción etnocéntrica de los mecanismos de regulación jurídica, que justifica todo su planteamiento de regulación a partir de la "Ley natural". Al no reconocer la capacidad de darse normas o de comportarse guiados por normas, estos pueblos no presentan sino una suerte de comportamientos instintivos, sin que opere ninguna forma de dar sentido a su comportamiento en función de su propia creatividad cultural. 
indios de Norteamérica (cf. $\$ 30$ ), y en general de las sociedades tradicionales ${ }^{13}$; por tanto, ese destino universal de los bienes no es para el género humano en sentido realmente universal, es para aquellos hombres trabajadores y racionales que se encuentran entre los primeros y no para los segundos, que son avariciosos, peleadores y disputadores. Locke en su Ensayo sobre el entendimiento humano (1980) [1690] nos dice que conocimiento y abundancia están en pugna. En el "vasto continente de América", donde abunda toda clase de riquezas naturales, están en situación de "ignorancia los antiguos salvajes americanos" (Locke, 1980). Y ello, no por falta de "talento natural" de éstos ${ }^{14}$, sino por falta de aplicación del conocimiento verdadero o "las investigaciones de los hombres racionales en pos de los verdaderos avances de la ciencia" (ib.), que se da en las naciones florecientes o parte civilizada de la humanidad.

Esta capacidad de trabajo racional, que emplea la creciente tecnología, es para Locke una conquista progresiva de la humanidad, que en realidad sólo se halla cultivada por la civilización a la que él pertenece. Tanto las "selvas de América como las escuelas de Atenas producen hombres de capacidades diversas dentro de la misma especie" (Locke, 1992). Y ello por la diversa capacitación que permiten los diversos contextos. Las diferencias "entre los entendimientos no proceden tanto de sus facultades naturales como de los hábitos adquiridos" (ib.). En este sentido, señala que "no todos los americanos [aborígenes] han nacido con entendimiento peores que los europeos, aunque vemos que ninguno de ellos hace tales investigaciones en las humanidades y en las ciencias" (ib.). Por ello, la naturaleza sólo nos da semillas, "hemos nacido para ser, si queremos, seres racionales, pero sólo el hábito y el ejercicio nos hacen serlo ( $y$ de hecho, somos así nada más que porque la industria y la aplicación nos ha llevado a serlo)" (ib.). Dado que ciertos seres humanos no cultivan la ciencia y la técnica al modo europeo, no tienen posibilidad de desarrollar comportamientos racionales y un trabajo que permita optimizar la abundancia de la

13. Las cuales "viven alejados de las nociones, discursos y avances del resto de la humanidad; (...) esos pueden muy bien compararse a los habitantes de las Islas Marianas, quienes (al estar separados por una gran extensión de mar de todo contacto con las partes habitadas de la Tierra), se creyeron las únicas personas del mundo. Y, aunque las escasas comodidades de vida entre ellos no llegaban al uso del fuego hasta que los españoles, no muchos años después, en sus viajes de Acapulco a Manila, se lo mostraron; todavía, en la necesidad y en la ignorancia de la mayoría de las cosas, se miraban a sí mismos, aun después de que los españoles les trajeran información de una variedad de naciones ricas en ciencias, artes y comodidades de vida, de las que ellos no sabían nada; se miraban a sí mismos, decía, como las personas más felices y más sabias del universo. Pero, a pesar de todo, creo que nadie se los imaginará como profundos físicos y sólidos metafísicos. Nadie estimará que el más avispado de ellos tenga opiniones muy amplias en ética o política; ni puede nadie conceder que el más brillante de ellos progrese tanto en su entendimiento como para tener ningún otro conocimiento más que unas cuantas pequeñas cosas sobre su isla (...) pero siempre bastante lejos de ese amplio desarrollo de la mente que embellece a un alma dedicada a la verdad, ayudada por la cultura y por las distintas opiniones de los pensadores de todas clases", (Locke, 1992).

14. Pues "en nada se quedan cortos sobre las naciones más florecientes y políticas" (ib.). 
naturaleza, lo que hoy llamaríamos la riqueza de la biodiversidad. Al no representar y cultivar la verdadera racionalidad humana, el uso y apropiación de los recursos naturales debe privilegiar a los sujetos que culturalmente están capacitados para obtener utilidades de ellos, y así beneficiar al "género humano". Quiénes son entonces los que deben disfrutar de las prerrogativas del género humano: la parte civilizada de la humanidad.

\subsection{Tercera reducción: El trabajo y la técnica humana patrimonio exclusivo de los pueblos europeos}

Lo anterior, es decir, la reducción interesada de lo que debe corresponder a la humanidad a una parte de la misma, trae causa de otra reducción, como ya se ha podido entrever. Se trata de una reducción cultural de la capacidad tecnológica del trabajo humano ${ }^{15}$, que desde una perspectiva no etnocéntrica, al contrario de Locke, sí sería común a toda la especie humana. El trabajo humano como actividad humana específica es una actividad que supone en parte la transformación y el control del medio en función de las necesidades de producción y reproducción de la vida humana de cualquier sujeto humano, ya sea que esté inserto en sociedades tradicionales o en sociedades tecnológicamente avanzadas, y sin el cual ninguna sociedad sobrevive. Este trabajo humano opera a través de la técnica, que podemos conceptuar como "manejo de realidades"16; pues bien, ese trabajo humano en función de las necesidades de sobrevivencia, a través de la técnica humana como manejo de las realidades con las que nos enfrentamos en el medio, es circunscrito o reducido, dentro de la sociedad burguesa, a la acción tecnológica propia de su formación

15. Sobre una visión sobre el trabajo humano, como la que adoptamos aquí, radicalmente diversa a la lockeana o liberal, véase Ellacuría (1990: 78 y ss).

16. Como destaca Ellacuría, siguiendo el análisis de la praxis humana de Zubiri, que entiendo supera el reduccionismo etnocéntrico de asimilar toda posibilidad de técnica humana como "técnica avanzada"; cualquier comportamiento humano tiene habérselas con el medio para que siga siendo biológicamente viable, en esa relación el ser humano "va arbitrando modos de sobrevivir, haciendo lo que en cada momento su grado de inteligencia le permite hacer. Inteligencia de la realidad e instrumentalización desde la realidad y para la realidad se dan así la mano. Desde esa primaria necesidad el hombre se lanza a modificar las cosas; las modifica para seguir viviendo, para poseerse a sí mismo en la modificación misma de las cosas" (2001:75). El hacer técnico nace para que la propia vida siga siendo viable. En este sentido, la técnica es el modo específico del trabajo humano: el trabajo es formalmente técnico. Por ello, "trabajo y humanidad son, en principio, dos realidades correlativas; no en vano el descubrimiento arqueológico de instrumentos de trabajo es prueba inequívoca de la presencia del hombre. El trabajo es verdaderamente trabajo cuando es acción transformadora por parte del animal de realidades, que lleva a la dominación del medio y con ello a la liberación de la vida humana" (2001: 78).

Ahora bien, la "dominación" o control del medio para asegurar la sobrevivencia biológica, como motor del trabajo técnico de cualquier sociedad humana, se puede operar de diversas formas en cada contexto cultural. Hay dos polos extremos para ello, como señalamos en este trabajo, el control "autocentrado", que tendencialmente propone al ser humano no sólo como "ser superior", sino como un ser que está más allá de las condiciones de sobrevivencia que le permite el medio, y que por ello, puede desplegar su actividad incluso destruyendo el medio natural en el que opera; o el control "descentrado" que, más allá de la conceptuación que se tenga de sí mismo, entiende que no puede hacer compatible la subsistencia humana con el irrespeto del medio natural, en última instancia, con su aniquilación. 
cultural, como nos indican los anteriores pasajes.

A partir de ahí, podemos entender por qué, por ejemplo, un tipo particular de arroz que se cultiva en una región de la India, que ha sido generado mediante la selección y control de semillas a lo largo de siglos, en un proceso histórico-social muy complejo y largo, no es considerado como "producto humano", sino solo como "recurso natural", por cuanto se argumenta que no ha sido sacado de su condición natural, por ende, pertenece a todos hasta que no sea descifrado genéticamente y patentada su secuencia. Cuando se descifra y manipula genéticamente desarrollando con ello una acción tecnológicamente avanzada sobre ese producto; entonces, ello da derecho a su explotación comercial privativa, en manos de los titulares legales que tendrían la licencia de uso y explotación comercial de ese producto, con el derecho de excluir de ese uso a quien no pague el canon correspondiente, incluidas aquellas comunidades que secularmente ha utilizado y producido ese producto. Pero esto no es considerado legalmente ningún robo. ¿Por qué no es un robo? Porque es un "recurso natural" y las empresas biotecnológicas no hacen sino en sentido lockeano servirse de lo que la naturaleza da gratuitamente. Por tanto, hay una invisibilización de la acción tecnológica propia de las sociedades tradicionales y del trabajo humano de esas sociedades. En este sentido, lo que importa no es el trabajo socialmente aplicado a un producto ni la técnica tradicional empleada para su obtención, pues ésta no se considera una actividad humana específica porque no deja ninguna huella de propiedad sobre ella. En cambio, ¿cómo se apropia el hombre de estos bienes en el esquema liberal clásico, en el esquema lockeano? Mediante el trabajo es la actividad por la cual lo saca del estado común de naturaleza, pero no vale cualquier trabajo para poner la huella de propiedad sobre la tierra y sacar las utilidades exigibles.

En este contexto, es interesante lo que dice Locke, hablando de la sociedad inglesa y de los otros pueblos: "un acre de tierra que aquí produce veinte bushels de trigo, y otro que, en América, con la misma labranza, produjese lo mismo, son sin duda alguna de un intrínseco valor natural idéntico. $Y$, sin embargo, el beneficio que recibe la humanidad del primero tiene un valor de 5 libras anuales, mientras que el segundo ni siquiera valdría un penique si todo el beneficio que un indio recibiese de él fuese valorado y vendido aquí; podría decirse con verdad que no valdría ni una milésima parte” (\$ $\$ 43$ ). Y ello, porque es el trabajo lo que pone en la tierra gran parte de su valor. Pero es la tecnología aplicada lo que da valor y no el simple trabajo, que no se considera una transformación material sino como creación técnica aplicada, y los portadores de la técnica son únicamente los europeos. Por ello, señala que hay muchos trabajos, pero sobretodo hay que considerar el de quienes fabricaron el arado, el de quienes construyeron cualquiera de los numerosísimos utensilios aplicados a la producción (cf. \$43); por tanto, no importa el valor natural de las cosas, ni ciertas intervenciones humanas sobre las mismas, sino la tecnología, aplicada o implementada en ellas. 
Ahora bien, todo se debe al "avance individual", no hay ningún proceso de enriquecimiento social a partir del cual se generan y posibilitan ciertas innovaciones, que en realidad se plantean como absolutas novedades y no se entienden a partir de un cierto estado del conocimiento sino como una suerte de genialidad aislada, que no se explica cultural ni socialmente por eso, no hay "innovación social" sino "inventores": "Aquel que inventó el primero la imprenta, el que descubrió el uso del compás, o hizo público las virtudes y el uso adecuado de la quinina, han contribuido más a la propagación del conocimiento, a la provisión y aumento de útiles, y a la salvación de los hombres que quienes construyeron colegios, casas de labor y hospitales" (Locke, 1980). A partir de ese reconocimiento, la humanidad debe tanto a los "inventores", aunque éstos no le deban nada a la humanidad, que ese trabajo supremo debe ser recompensado, como por ejemplo, asegura el derecho de propiedad sobre las invenciones, es decir, las patentes ${ }^{17}$.

Sin intervención del pensamiento y la reflexión no hay artificio, y donde no lo hay, todo es simplemente "natural". Podría aplicarse esta distinción al problema de la técnica y la división de la humanidad. Los hallazgos o "invenciones" de las sociedades tradicionales, desde un punto de vista etnocéntrico, por obvias e irreflexivas, no dejan de recaer sobre productos naturales que son "sacados de su condición natural", y por ello no ponen en ellos "ninguna huella de propiedad". En cambio, los "numerosísimos utensilios" que el desarrollo tecnológico de la parte civilizada de la humanidad aplica sobre los recursos naturales deja en ellos la huella de la propiedad.

\subsection{Cuarta reducción: la mercantilización de la tierra y los bienes naturales}

La satisfacción de necesidades mediante la utilización de los bienes naturales, vinculada con el llamado valor de uso de los bienes, es algo que Locke al comienzo de su planteamiento reconoce, sin embargo, de ese reconocimiento consigue llegar a un punto en que toda la funcionalidad económica para la vida humana en sociedad de los bienes naturales queda subsumida únicamente en el precio como valor de cambio. Reducida la función social de un bien a su expresión monetaria, y con ello a la carestía que alcance, se olvida la lógica del sustento de la vida que estaba en el origen de la apropiación originaria.

En este sentido, hablamos de una reducción mercantilista. En el esquema lockeano, para

17. Así por ejemplo, como analiza Velásquez, la propia lógica jurídica del sistema ADPIC fuerza que las patentes con una duración mínima de 20 años se apliquen sobre los productos de las industrias farmacéuticas privadas para que sigan investigando. Se argumenta el coste de la investigación, que será financiada por las patentes, que al garantizar a las empresas un monopolio, les permite mantener precios elevados. Ahora bien "estos precios impiden que la mayoría de las personas que necesitan estos nuevos productos puedan procurárselos. Si bien hay que preservar la investigación y el desarrollo de nuevos medicamentos, también es esencial que éstos puedan salvar vidas a partir del momento de su descubrimiento y no veinte años después... excepto que se perpetúe la absurda situación actual, en la cual millones de personas mueren por falta de medicamentos, que sin embargo existen y que la sociedad podría poner al alcance de todos" ( 2003:25). 
que la tierra y los bienes naturales sean socialmente útiles, no expuestos o dejados para la avaricia de las sociedades tradicionales, tienen que ser apropiados privativamente y rentabilizados, o "puestos en valor" mediante el uso del dinero; así se logra, según él, disponerlos para el beneficio común. Porque el uso del dinero en la gestión de estos "recursos naturales" y en la apropiación privativa es lo que permite la "utilidad" para el género humano. Dice Locke: "Al principio la mayoría de los hombres se contentaban con lo que la desnuda naturaleza les ofrecía para satisfacer sus necesidades, sin embargo, en algunas partes del mundo, donde mediante el uso del dinero habian hecho que la tierra escaseara y que por lo tanto, tuviese algún valor, regularon las propiedades de los individuos de su sociedad" (\$45). Entonces, hasta que no se regulan las propiedades de los individuos en la sociedad, y hasta que no se mercantilizan esas propiedades y se vuelven intercambiables por dinero, no hay una utilidad para el género humano. Por eso se habla de una reducción mercantilista.

Esta reducción opera mediante una invisibilización y pérdida del sentido de la función natural de la tierra y, por ende, de los recursos. En el fondo, se trata de que la tierra y los recursos naturales son casi prescindibles en función del trabajo tecnológicamente avanzado. Este pretende reemplazar las fuentes naturales, por eso llega a decir Locke, ya en el siglo XVII, que "la tierra que proporciona las materias primas es de escaso valor, si es que tiene alguno" (\$42). En consecuencia, hay una desconexión y una pérdida del sentido del valor de uso y de satisfacción de necesidades a través de esos "recursos naturales", que resultan ser los menos valiosos, y a su vez, de la función que tiene toda la naturaleza en el sustento de la vida. Cuando se reduce toda la relación con la naturaleza a un puro cálculo de utilidad, se invisibiliza cualquier otra funcionalidad de la misma, y se entiende que si no se instrumentaliza mediante la mercantilización; por ello, nos dirá que si ese no es el modo de actuar, "el beneficio que de ella se deriva es prácticamente nulo" (cf. \$42).

\subsection{Quinta reducción: la pérdida de la interdependencia o de la racionalidad reproductiva}

Hay otro supuesto, en todo este esquema, que es la pérdida de la racionalidad reproductiva ${ }^{18}$. La racionalidad reproductiva es aquella por la cual se mantiene unida, en relación de interdependencia, la acción humana con el medio natural. Es algo que las sociedades tradicionales saben bien y que expresan en su propia sabiduría popular. Hay un discurso famoso del jefe Seatle, el indio norteamericano que decía: "Nosotros sabemos esto: la tierra no pertenece al hombre, el hombre pertenece a la tierra, nosotros sabemos esto: todas las cosas están relacionadas, como la sangre que une a la familia, todo lo que suceda a la tierra sucede a los hijos de ésta, lo que él hace a este tejido se lo hace a sí mismo".

18. Sobre la racionalidad reproductiva véase Hinkelammert (2002) y Hinkelammert y Mora (2002). 
El derecho de propiedad privada, lo sabemos desde el derecho romano, es el derecho de disfrute, uso y abuso de las cosas poseídas (ius fruendi, utendi et abutendi); entonces, si se destruyen las cosas poseídas, supuestamente no destruimos al poseedor. En cambio, las sociedades tradicionales, en virtud de su visión de una racionalidad que nos prescinde de la interdependencia, saben que si no respetamos las cosas poseídas no respetamos tampoco al poseedor. Esto ayuda a explicar porqué cuesta tanto trabajo a las sociedades tradicionales asumir o adoptar la mercantilización de sus recursos biológicos y la lógica de la inscripción registral de estos, porque en el fondo es una lógica que desvincula las cosas de su valor de uso y abusando de ellas solo las considera en tanto que mercancía intercambiable.

Pero una posición de este tipo está fuera de la visión de esta apropiación tecnológica de los "recursos naturales", conforme a la cual se pretende que no dependemos de la naturaleza si ya hemos conseguido dominarla por el conocimiento, hoy día, descifrando la información genética que contiene. Con esta información, teóricamente, podremos reproducir el mundo tecnológicamente y la vida natural. Asimismo, se puede agredir a la naturaleza porque el ser humano está más allá de la naturaleza, y cree que si destruye este tejido no se destruye a sí mismo, lo que es propio de una racionalidad que prescinde de las condiciones de sobrevivencia.

Son todas estas reducciones y escisiones examinadas las que justifican ese proceso de colonización del mundo europeo tradicional en primer término, y del resto de mundos de la humanidad después.

\section{EL DERECHO A LA CULTURA EN EL CONTEXTO ACTUAL: LUCHAS Y ACTORES EMERGENTES}

El apartado anterior nos ha introducido en los conflictos que históricamente se han dado entre pueblos originarios y el proceso colonial de la mano del proyecto de sociedad moderna. La disminución o negación antropológica de los otros junto con la invisibilización de su sistema cultural para regular y dar sentido a todos los subsistemas prácticos de estas sociedades; en sus relaciones sociales, jurídicas, políticas, económicas, ecológicas o espirituales. Esto supone el ejercicio de una violencia que los declara incapaces de autodeterminarse como sociedades humanas. Por eso, toda fuente de normatividad ha de venir de la mano de la "civilización de los pueblos europeos (modernos)". Desde este monismo cultural, se funda un monismo jurídico, que no sólo tiene un carácter públicoestatal sino también de derecho privado conforme a la lógica de la modernidad liberal, que vehicula ese proyecto de sociedad moderna. Si las otras sociedades quieren proteger sus creaciones culturales habrán de utilizar los instrumentos jurídicos de la modernidad liberal. Pero los instrumentos jurídicos no son neutrales culturalmente y están cargados de consecuencias que transforman el sentido cultural que las sociedades dan a su propio patrimonio, transformando finalmente el propio proyecto de sociedad tradicional. Por 
ello, el "derecho al patrimonio cultural" se funda en el "derecho a la cultura", y éste en el proceso mismo de autodeterminación cultural de cada sociedad ${ }^{19}$, que puede generar su propio modo de situarse en el mundo que da lugar a su propio sistema de organización y de protección de su "patrimonio cultural". Tras las luchas jurídicas, están las luchas culturales por poder seguir autodeterminándose frente a la violencia etnocida del proyecto moderno.

Para ello, tratan de mantener una relación tensa con los instrumentos institucionales y jurídicos modernos, que se puede articular en tres vertientes que en el fondo responden a un mismo proyecto de resistencia y autoafirmación. Primera, afirmando sus propias instituciones y regulaciones frente a las instituciones modernas. Segunda, criticando y denunciando los mecanismos sociales y jurídicos más disfuncionales o erosionadores de su propio proceso cultural. Tercera, tratando de ponerlos en su caso al servicio de su propio proceso social. Se da así un proceso complejo, de afirmación instituyente y alternativo de su propia autonomía institucional y jurídica, uso de las instituciones y sistemas jurídicos modernos para protegerse o aminorar el impacto negativo en sus sociedades y crítica de los sistemas anuladores.

¿Cuál es el contexto actual de las luchas entre los diferentes actores y marcos sociojurídicos actuales?

Tras el proceso de modernización de las sociedades tradicionales y la fundación de los estados nacionales como modo de vehicular la transformación social, los grupos sociales tradicionales no asimilados siguen tratando de resistir y de mantener su propio proceso cultural autónomo. Por tanto, hay un nivel "local" o estatal de conflicto entre actores hegemónicos y actores subalternos; pero a su vez hay un campo de luchas "global" o internacional. En el nivel trasnacional, podemos aludir a dos grandes espacios, el derecho internacional público y del derecho de los pueblos, donde los pueblos originarios tratan de hacerse oír y de ser reconocidos (en la línea del Convenio 169 de la OIT Sobre Pueblos indígenas y tribales en países independientes de 1989); y para ello pueden usar los instrumentos jurídicos e instituciones del derecho internacional de los derechos humanos (v. gr., Corte Interamerinana de Derechos Humanos para hacer valer los Pactos Internacionales de Derechos Humanos) ${ }^{20}$. Así, (Berraondo, 2004) se habla de una derecho internacional emergente de los pueblos indígenas (Sánchez Rubio y Solórzano Alfaro, 2004).

19. Para una compresión del derecho desde las prácticas sociales y no puramente formalista y substancialista, como proceso dinámico y continuo con una dimensión instituyente, instituida y transformador de lo instituido puede verse Senent (2011).

20. El Caso de la Comunidad Mayagna (Sumo) Awas Tingni Vs. Nicaragua ante la Corte Interamericana de Derechos Humanos, Sentencia de 31 de agosto de 2001, representa un importante precedente para el reconocimiento jurídico de las propias instituciones indígenas u originarias de los pueblos minorizados (http://www.corteidh.or.cr/docs/casos/articulos/seriec 79 esp.pdf). 
Pero a su vez, hay otro espacio global de normatividad iusprivatista que regula las relaciones económicas y productivas y que entra en conflicto con la cosmovisión e intereses de los pueblos originarios, y que se puede simbolizar en el Acuerdo sobre Aspectos de los de los derechos de propiedad intelectual relacionados con el comercio (ADPIC) de la Organización Mundial del Comercio de la OMC de $1994^{21}$, y al que en el apartado anterior hemos hecho referencia.

En el campo específico de los instrumentos internacionales de los derechos humanos, y que los pueblos originarios en relación con el proceso cultural pueden poner a su servicio, hay que partir de la Declaración Universal de Derechos Humanos de Naciones Unidas de 1948, donde en su artículo 27 se proclama el derecho de la persona (individual) a "tomar parte libremente en la vida cultural de la comunidad". Estamos todavía en un marco normativo restrictivo al tomar como punto de partida al individuo como instancia central y única de reconocimiento. Su desarrollo normativo a partir del Pacto Internacional de Derechos Económicos, Sociales y Culturales de $1966^{22}$, permite abrir nuevas posibilidades al reconocer en su artículo 1 el derecho a la libre determinación de los pueblos: "Art.1. 1. Todos los pueblos tienen el derecho de libre determinación. En virtud de este derecho establecen libremente su condición política y proveen asimismo a su desarrollo económico, social y cultural. 2. Para el logro de sus fines, todos los pueblos pueden disponer libremente de sus riquezas y recursos naturales, sin perjuicio de las obligaciones que derivan de la cooperación económica internacional basada en el principio de beneficio recíproco, así como del derecho internacional. En ningún caso podrá privarse a un pueblo de sus propios medios de subsistencia”. Otro hito normativo es la Declaración Universal de la UNESCO sobre Diversidad Cultural (2001), donde se defiende el pluralismo cultural a nivel político como modo de construir unas relaciones justas en el contexto de las sociedades culturalmente diversas: "Artículo 2 - De la diversidad cultural al pluralismo cultural. En nuestras sociedades cada vez más diversificadas, resulta indispensable garantizar una interacción armoniosa y una voluntad de convivir de personas y grupos con identidades culturales a un tiempo plurales, variadas y dinámicas. Las políticas que favorecen la inclusión y la participación de todos los ciudadanos garantizan la cohesión social, la vitalidad de la sociedad civil y la paz. Definido de esta manera, el pluralismo cultural constituye la respuesta política al hecho de la diversidad cultural. Inseparable de su contexto democrático, el pluralismo cultural es propicio a los intercambios culturales y al desarrollo de las capacidades creadoras que alimentan la vida pública"23.

\section{1. http://www.wto.org/spanish/docs s/legal s/27-trips 01 s.htm}

22. Pacto Internacional de Derechos Económicos, Sociales y Culturales (http://www2.ohchr.org/ spanish/law/cescr.htm).

23. Esta Declaración es desarrollada jurídicamente por la Convención sobre la protección y la promoción de la Diversidad de las Expresiones Culturales, UNESCO, 2005 (http://unesdoc.unesco.org/ images/0014/001429/142919s.pdf). Sobre estas cuestiones es relevante la monografía de Barreiro (2011). 
Junto a estos instrumentos jurídicos internacionales, que tienen un carácter ambiguo aunque pueden ser puestos al servicio de la protección de la vida social y cultural de los pueblos originarios, hay que destacar otros instrumentos en un plano normativo más radical al suponer un intento de reconocimiento público instituyente frente a la secular exclusión de los sistemas jurídicos hegemónicos hacia estas sociedades. Berraondo (2004) describe las respuestas indígenas ante las amenazas a la autodeterminación cultural, y en particular a su propiedad intelectual y cultural. En este contexto hay toda una serie de declaraciones de pueblos indígenas que expresan la autocomprensión y la defensa jurídica de su proceso cultural, que han ido surgiendo en respuesta a las amenazas y agresiones que en las últimas décadas han sufrido. A partir de 1992, en el contexto de la memoria de los 500 años de resistencia indígena frente al proceso de colonización, y particularmente en el contexto del Convenio de Rio de Janeiro sobre la diversidad biológica, se sitúa como autoafirmación de la Declaración de KARI-OCA, que es firmada por los indígenas de los cinco continentes presentes en esta Conferencia Mundial de los Pueblos Indígenas: "Nosotros, los Pueblos Indígenas, caminamos hacia el futuro sobre las huellas de nuestros ancestros. Desde el más pequeño hasta el más grande de los seres vivientes, desde las cuatro direcciones, desde el aire, la tierra y las montañas, el creador nos ubica a nosotros - los Pueblos Indígenas- sobre nuestra madre la Tierra. Las huellas de nuestros ancestros están grabadas para siempre sobre las tierras de nuestros Pueblos. Nosotros, los Pueblos Indígenas, mantenemos nuestros derechos inherentes a la autodeterminación. Nosotros siempre hemos tenido el derecho a decidir nuestras propias formas de gobierno, a usar nuestros propios modos de criar y educar a nuestros hijos, a nuestra propia identidad cultural sin interferencias. Nosotros continuamos manteniendo nuestros derechos como pueblos a pesar de los siglos de privaciones, asimilación y genocidio. Nosotros mantenemos nuestros derechos inalienables a nuestras tierras y territorios, a todos nuestros recursos -sobre y debajo de la tierra- y a nuestros ríos, lagos y mares. Nosotros reafirmamos nuestro compromiso de pasarlos a las generaciones futuras. Nosotros no podemos ser removidos de nuestras tierras. Nosotros, los Pueblos Indígenas, estamos conectados a través del círculo de la vida a nuestras tierras y medio ambientes. Nosotros, los Pueblos Indígenas, caminamos hacia el futuro sobre las huellas de nuestros ancestros"24.

A lo largo de los siguientes años se han ido sucediendo declaraciones y propuestas que son respuestas contextuales a las diferentes amenazas sentidas y en las que se avanza en

24. "Pueblos indígenas" (1992), Declaración de KARI-OCA, hecha en Río de Janeiro. (http://www. dialoguebetweennations.com/ir/espanol/KariOcaKimberley/KODeclaracion.html 
el proceso de contestación a los mecanismos jurídicos regulatorios en los que quedan marginados o marginados de su propia capacidad de ser sujetos de derecho en un sentido plenario $^{25}(25)$.

25. "Pueblos indígenas" (1992):

-Declaración del Mataatua (1993) de Los Derechos Intelectuales y Culturales de Los Pueblos Indígenas en Whakatane, Aotearoa. New Zealand (http://www.prodiversitas.bioetica.org/doc23.htm )

-Propuesta Comunitaria (1994) sobre variedades vegetales de la Red del Tercer. Propiedad Intelectual Comunitaria. Mundo. (http://www.prodiversitas.bioetica.org/doc64.htm)

- Declaración de Santa Cruz de la Sierra y Plan de Acción para el Desarrollo Sostenible de las Américas (1996). Santa Cruz de la Sierra, Bolivia. (http://www.summit-americas.org/summit_sd/ summit sd poa sp.pdf)

- Declaración de Ukupseni, Kuna Yala Sobre el Proyecto de Diversidad del Genoma Humano (1997) (http://www.nativeweb.org/papers/statements/science/hgdp1.php ). Sudáfrica.

-Plan de aplicación de los pueblos indígenas sobre desarrollo sostenible (2002) Johannesburgo,

(http://www.johannesburgsummit.org/html/documents/summit docs/131302 wssd report reissued.pdf)

-Declaración de Buenos Aires sobre el Conocimiento Tradicional, los Derechos Indígenas y los Sistemas de Propiedad Intelectual (2003).(http://www.indigenas.bioetica.org/declaracion.htm) 


\section{REFERENCIAS BIBLIOGRÁFICAS}

ASAMBLEA GENERAL DE NACIONES UNIDAS (1966) Pacto Internacional de Derechos Económicos, Sociales y Culturales (http://www2.ohchr.org/spanish/law/cescr. htm. Consultado 15 noviembre de 2011)

BARREIRO, B. (2011) La diversidad cultural en el derecho internacional: La Convención de la UNESCO, Madrid: IUSTEL.

BERRAONDO, M. (2004) "Nuevos retos para los pueblos indígenas. Propiedad intelectual y corporaciones transnacionales" en D. Sánchez Rubio y N. Solórzano Alfaro (Eds.) Nuevos colonialismos del capital. Propiedad intelectual, biodiversidad y derechos de los pueblos. Barcelona: Icaria.

CORTE INTERAMERICANA DE DERECHOS HUMANOS (2001) Caso de la Comunidad Mayagna (Sumo) Awas Tingni Vs. Nicaragua. Sentencia de 31 de agosto de 2001 (http://www.corteidh.or.cr/docs/casos/articulos/seriec 79 esp.pdf, Consultado 15 noviembre de 2011)

ELLACURÍA, I. (1990) Filosofía de la realidad histórica, Madrid: Trotta.

ELLACURÍA, I. (2001) [1975] “El trabajo humano como técnica”, en Persona y Comunidad, Isidorianum, $\mathrm{n}^{\circ} 19$.

ELLACURÍA, Ignacio (2012) [1969-1989] La lucha por la justicia (en prensa), Bilbao: Universidad de Deusto.

HINKELAMMERT (2002) Crítica de la razón utópica, Bilbao: Desclée de Brouwer.

HINKELAMMERT y MORA (2002) Coordinación social de trabajo, mercado y reproducción de la vida humana, San José: DEI.

LOCKE, J. (1980) [1690] Un ensayo sobre el entendimiento humano, Madrid: Editora Nacional.

LOCKE, J. (1990) [1690] Segundo Tratado sobre el Gobierno Civil, Madrid: Alianza Editorial.

LOCKE, J. (1992) [1706] Sobre la conducta del entendimiento y otros ensayos póstumos, Barcelona: Anthropos.

ORGANIZACIÓN INTERNACIONAL DEL TRABAJO (1989) Convenio 169 Sobre Pueblos indígenas y tribales en países independientes.

(http://www.ilo.org/public/spanish/region/ampro/lima/publ/conv-169/convenio.shtml. Consultado 15 noviembre de 2011). 
ORGANIZACIÓN MUNDIAL DEL COMERCIO (1994) Acuerdo sobre Aspectos de los de los derechos de propiedad intelectual relacionados con el comercio (ADPIC) (http:// www.wto.org/spanish/docs s/legal s/27-trips 01 s.htm. Consultado 15 noviembre de 2011)

POLANYI, K. (1997) La gran transformación. Crítica del liberalismo económico. Madrid: La piqueta.

PUREZA, J.M. (2002) El patrimonio común de la humanidad ¿Hacia un Derecho internacional de la solidaridad?, Madrid: Trotta.

SÁNCHEZ RUBIO, D. y SOLÓRZANO ALFARO, N. (2004) "Nuevos colonialismos del capital. Propiedad intelectual, biodiversidad y derechos de los pueblos", en Revista Hiléia. Revista de Direito Ambiental da Amazonia, n², pp. 35-60.

SENENT, J.A. (1998) Ellacuría y los derechos humanos, Bilbao: Desclée de Brouwer.

SENENT, J.A. (2004) "Sociedad del conocimiento, biotecnología y biodiversidad" en Revista Hiléia. Revista de Direito Ambiental da Amazonia, n², pp. 115-144.

SENENT, J.A. (2010), "Naturaleza y tierra en el horizonte de la subjetividad moderna" en Revista de Fomento Social, no 257, pp.33-56.

SENENT, J.A. (2011), "El ajuste o desajuste de las prácticas normativas en Ignacio Ellacuría: hacia una nueva dimensión de lo normativo" en Anuario de Filosofía del Derecho.

SHIVA, V. (2003) ¿Proteger o expoliar? Los derechos de propiedad intelectual, Barcelona: Intermón Oxfam.

UNESCO (2005) Convención sobre la protección y la promoción de la Diversidad de las Expresiones Culturales, (http://unesdoc.unesco.org/images/0014/001429/142919s.pdf. Consultado 15 noviembre de 2011).

VELÁSQUEZ, G. (2003) "El medicamento como bien público mundial", Le monde diplomatique, edición. española, nº 93. 